\title{
Ochratoxin A, fungal contamination and antioxidant property of defective Arabica coffee in Benguet, Philippines
}

\author{
Jonathan M. Barcelo ${ }^{1 *}$, Racquel C. Barcelo², Andrea A. Alvarez ${ }^{1}$ \\ ${ }^{1}$ Department of Medical Laboratory Science, School of Natural Sciences, Saint Louis University, Baguio City, Philippines 2600, ${ }^{2}$ Department of \\ Biology, School of Natural Sciences, Saint Louis University, Baguio City, Philippines 2600
}

\section{A B S T R A C T}

\begin{abstract}
In Benguet, Philippines, efforts have been made to improve the production of high quality Arabica coffee beans (Coffea arabica). However, defects in coffee beans may still occur during post-harvest processing. Since defective coffee beans decrease the quality of coffee brews, they are commonly consumed in the municipality as beverage and are not sold commercially. In this study, the incidence of fungal and ochratoxin A contamination, in green and roasted immature and black defective coffee beans were investigated. Furthermore, the antioxidant properties of defective coffee beans were evaluated using a radical scavenging assay and metal chelating assay. It was found out that green coffee bean samples were contaminated with ochratoxigenic fungi and ochratoxin A. Roasting the green coffee bean samples decreased their total phenolic content, but increased their radical scavenging and metal chelating activities. The antioxidant activities, however, were statistically lower than standard antioxidants such as L-ascorbic acid, gallic acid and ethylene diamine tetraacetic acid $(\rho<0.05)$. Ochratoxin A levels in defective green coffee beans also decreased after roasting. While phenolic compounds contribute to the antioxidant activities of the green coffee beans, the antioxidant activities of roasted coffee beans may be attributed to other antioxidant compounds formed during roasting. There is a need to further process contaminated defective coffee beans prior to utilization to isolate antioxidant compounds and remove ochratoxin $A$.
\end{abstract}

Keywords: Antioxidant; Arabica coffee variety; Defective coffee beans; Fungal contamination; Ochratoxin A

\section{INTRODUCTION}

Coffee is globally recognized as a popular beverage with well-documented in vitro antioxidant activities (Ramalakshmi et al., 2009; Liang and Kitts, 2014; Górnaś et al., 2016). In the Philippines, Benguet ranks third among the provinces in the Cordillera Administrative Region with the highest coffee production, with Arabica coffee variety grown in backyard or commercial coffee farms (Culliao and Barcelo, 2015). In an effort to minimize fungal contamination of coffee, wet processing is practiced by coffee growers in several areas of Benguet (Alvindia and Acda, 2010) and good agricultural practices are promoted by coffee farmers. However, the environmental condition in the province is characterized by low diurnal temperature and high humidity which may compromise efficient drying of parchment coffee. Furthermore, fungal contamination of coffee especially during post-harvest processing is common.
Fungal contamination can cause defects in coffee beans and may decrease the quality of coffee brew.

In Benguet, coffee is visually evaluated for defects based on size, colour, and presence of other imperfections. The defects in coffee beans are usually classified as black, sour or brown, immature, insect-damaged or bored beans (Franca et al., 2005a; Ramalakshmi et al., 2008). Several literatures have characterized the properties of defective coffee beans to improve the quality of commercial coffee. Published data on the characteristics of defective coffee were described using Fourier transform infrared spectroscopy (Craig et al., 2012), physical, organoleptic and chemical analysis (Franca et al., 2005a), and cup quality (Franca et al., 2005b) to distinguish them from non-defective coffee beans. However, these methods are not common to coffee farmers and screening for coffee defects is only done visually, relying primarily on morphological or sensory properties as basis

\footnotetext{
${ }^{*}$ Corresponding author:

Jonathan M. Barcelo, Department of Medical Laboratory Science, School of Natural Sciences, Saint Louis University, Baguio City, Philippines 2600. E-mail: jonathanbrcl@yahoo.com
}

Received: 22 September 2016; Revised: 01 January 2017; Accepted: 02 January 2017; Published Online: 07 January 2017 
for the classification of coffee beans. Other parameters which are assessed to determine the quality of Philippine coffee beans include size, moisture content, smell, and presence of fungi among others (PNS/BAFPS 01:2012).

Efforts have been made to describe the incidence of ochratoxin A contamination in green coffee beans in Benguet (Culliao and Barcelo, 2015) and identification of potential ochratoxigenic fungi in several coffee-producing provinces in the Cordillera Administrative Region (Alvindia and de Guzman, 2016) due to an increasing demand for Philippine coffee. The production of coffee in the Philippines is managed by coffee organizations in several municipalities and supervised by municipal agricultural officers due to limitations in the availability of coffee processing facilities and lack of technical skills of coffee farmers.

Coffee beans which are classified as defective due to discoloration, mechanical damage or poor quality cannot enter the national and international market because the coffee beans affect the quality and aroma of the coffee brews. Instead, defective coffee beans are roasted carefully due to difficulty in producing an even roast and susceptibility of the coffee beans to charring. The roasting of coffee beans is done manually based from the visual chart in the Philippine National Standard for the specifications of green coffee beans (PNS/BAFPS 01:2012). Since defective coffee beans have low economic value, they are typically consumed as beverage and are not sold commercially.

In other countries, defective coffee beans have been tapped as potential sources of several phenolic compounds which exhibit antioxidant properties (Ramalakshmi et al., 2009; Gornas et al., 2016) and anti-tumour activities (Ramalakshmi et al., 2008). However, ochratoxin A was also reported to contaminate defective coffee beans (Taniwaki et al., 2014). Hence, this study investigated the incidence of ochratoxigenic fungal contamination, ochratoxin A content and potential antioxidant properties of defective Arabica coffee beans and the effects of roasting to these parameters.

\section{MATERIALS AND METHODS}

\section{Materials and reagents}

Methanol (analytical grade), n-hexane, sodium bicarbonate, acetonitrile (high performance liquid chromatography, HPLC grade), methanol (HPLC grade), acetic acid (HPLC grade), Saboraoud dextrose agar (SDA) media, Czapek yeast agar media, Folin-Ciocalteau reagent, dimethylsulfoxide, ochratoxin A (OTA) standard (10 $\mu \mathrm{g} / \mathrm{mL}$ in acetonitrile), gallic acid standard and L-ascorbic acid standard were purchased from Sigma Aldrich (Singapore). Immunoaffinity columns (OchraTest WB) were purchased from Milford, USA.

\section{Coffee samples}

Three kilos of defective green coffee beans and one kilo of non-defective green coffee beans were obtained from Caliking, Atok, Benguet, Philippines last January 2016. The samples were packed into low density polyethylene plastic bags and delivered immediately to Saint Louis University Natural Sciences Research Unit (SLU-NSRU), Baguio city, Philippines. The coffee samples were sorted by coffee farmers into immature and black coffee beans following the Philippine National Standards specified for green coffee beans. The sorted samples were packed in polyethylene bags and stored in an ultra low freezer at $-20^{\circ} \mathrm{C}$ prior to preparation of coffee extracts.

\section{Preparation of coffee bean extracts}

For the preparation of green coffee bean extracts, 200 grams of each green coffee bean samples were placed in separate $500 \mathrm{~mL}$ beakers and ground using a coffee grinder. Another 200 grams of each coffee bean samples were sent to a roasting facility in Baguio city market. The coffee samples were roasted at $200^{\circ} \mathrm{C}$ for 30 minutes until the coffee beans samples were classified as medium roast by roasters according to the visual guide specified in PNS/BAFPS 01:2012. The roasted coffee samples were also ground using a commercial coffee grinder. In separated Erlenmeyer flasks, 20 grams of green and roasted coffee bean samples were extracted with $200 \mathrm{~mL}$ of $85 \%$ methanol solution for 48 hours. Extraction was repeated for the roasted coffee sample until the extracting solution was colourless. The mixtures was decanted, filtered twice with Whatman 1 filter paper $(0.45 \mu \mathrm{m})$, and defatted successively with $50 \mathrm{~mL}$ of $\mathrm{n}$-hexane per $100 \mathrm{~mL}$ of the crude extract in a separatory funnel. The defatted extracts were evaporated at $40^{\circ} \mathrm{C}$, collected in separate amber-coloured vials and stored in an ultra-low freezer at $-20^{\circ} \mathrm{C}$ prior to the antioxidant assays.

\section{Ochratoxin A analysis}

The method of Oliveira et al. (2013) was utilized in the study with few modifications. Twenty grams of coffee samples was placed in a $500 \mathrm{~mL}$ Erlenmeyer flask and soaked in $200 \mathrm{~mL}$ of $3 \%$ methanol: Sodium bicarbonate $(1: 1, \mathrm{v} / \mathrm{v})$ solution. The Erlenmeyer flask was sealed with paraffin film, and the system was sonicated for 20 minutes. The samples were filtered in Whatman grade no. 1 filter paper. A volume of $10 \mathrm{~mL}$ was mixed with $90 \mathrm{~mL}$ of phosphate-buffered saline solution $(\mathrm{pH} 7.10 \pm 0.10)$. The $100 \mathrm{~mL}$ extract was introduced to the immunoaffinity column (OchraTest WB) at a flow of 2 to $3 \mathrm{~mL} /$ minute using a glass syringe. The column was eluted with $2 \mathrm{~mL}$ of HPLC grade methanol. Back flushing was performed and the methanol remained in contact with the column resin for $3 \mathrm{~min}$. The eluate was 
collected in a $4 \mathrm{~mL}$ vial then evaporated in a water bath to remove the solvent. The remaining residue was redissolved in $1 \mathrm{~mL}$ of the HPLC mobile phase, filtered in a $0.2 \mu \mathrm{m}$ syringe filter and dispensed into HPLC vials. The vials were sent to Shimadzu Philippines Corporation, Taguig City, Philippines for the determination of ochratoxin A concentration using high performance liquid chromatography with fluorescence detection.

The HPLC conditions were based from the methodology of Batista et al. (2009). Quantification was carried out by using Shimpack CLC ODS (C18) $4.6 \mathrm{~mm} \times 25 \mathrm{~mm} \times 5 \mu \mathrm{m}$ HPLC column (Shimadzu) with a mobile phase of acetonitrile: methanol: water: acetic acid (35:35:29:1, v/v/v/v) and a flow rate of $1 \mathrm{ml}^{*} \mathrm{~min}^{-1}$. Fluorescence detection was performed with an excitation filter in $332 \mathrm{~nm}$ and emission at $476 \mathrm{~nm}$. The retention time of the coffee samples were compared to the retention time of ochratoxin A standard. Compound identity was determined using an ochratoxin A standard. Quantification of ochratoxin A in samples was performed using a calibration curve of the ochratoxin. A standard solutions using $0.05 \mathrm{ng}^{*} \mathrm{~mL}^{-1}$ to $1.0 \mathrm{ng}^{*} \mathrm{~mL}^{-1}$. The limit of quantification was calculated based on the signal-to-noise ratio of $0.05 \mathrm{ng}^{*} \mathrm{~mL}^{-1}$ OTA using ASTM method. The OTA levels of the sample were expressed as $\mu \mathrm{g}^{*} \mathrm{~kg}^{-1}$ sample. Analysis was performed in triplicate.

\section{Fungal analysis}

The method of Noonim et al. (2008) was utilized with modifications. A $20 \mathrm{~g}$ coffee sample was disinfected in a sodium hypochlorite solution $(0.4 \%)$ for 2 minutes. Preliminary identification was done using Saboraoud dextrose agar (SDA) Media. A total of 11 coffee beans were placed aseptically on SDA media with $1 \%$ Glendamycin. The plates were incubated for 7 days at $25^{\circ} \mathrm{C}$ then observed for hyphal growth and sporulation. The fungal growths were subcultured in Czapek yeast agar (CYA) Media with $1 \%$ Glendamycin for further identification. Morphological characteristics and microscopic features were evaluated based from the study of Samson et al. (2007).

\section{Determination of total phenolic content}

Total phenolic content was determined using the method described by Saeed et al. (2012). A 1000 $\mu \mathrm{g}^{*} \mathrm{~mL}^{-1}$ sample was mixed with $1 \mathrm{~mL}$ of Folin-Ciocalteau reagent. After 5 minutes, $5 \mathrm{~mL}$ of $7 \% \mathrm{Na}_{2} \mathrm{CO}_{3}$ solution was added followed by $13 \mathrm{~mL}$ of distilled water. The mixture was wrapped in aluminium foil 90 minutes. The absorbance of the mixture was determined at $750 \mathrm{~nm}$. A calibration curve using $62.5 \mu \mathrm{g}^{*} \mathrm{~mL}^{-1}$ to $1000 \mu \mathrm{g} * \mathrm{~mL}^{-1}$ gallic acid was used to estimate the concentration of total phenolic content in the coffee extracts. The total phenolic content was expressed as mg gallic acid equivalents per 100 gram of dry weight of extract (mg GAE*100g $\mathrm{g}^{-1} \mathrm{dW}$ ). The procedure was performed in five replicates at the Saint Louis University Natural Sciences Research Unit.

\section{DPPh radical scavenging activity}

The method was adapted from Clarke et al., (2013). Twenty microliters $(20 \mu \mathrm{L})$ of the extract was diluted in Dimethylsulfoxide (DMSO) with $180 \mu \mathrm{L}$ of DPPH in methanol $(40 \mu \mathrm{g} / \mathrm{mL})$ in wells of a 96-well plate. The plate was kept in the dark for 30 minutes after which the absorbance of the solution was measured at $540 \mathrm{~nm}$ in a plate reader. DMSO served as a blank and L-ascorbic acid served as the standard. Gallic acid was used as a comparison group to the coffee extracts. The procedure was performed in six replicates. The radical scavenging activity was computed using the formula:

$\%$ RSA $=\frac{\text { A control }- \text { A extract }}{\text { A control }} \times 100$

\section{Metal chelating activity}

The ability of extracts to chelate ferrous ion $\left(\mathrm{Fe}^{2+}\right)$ was adapted from Le et al. (2007). The assay measures the chelating activity of the sample by its ability to remove $\mathrm{Fe}(\mathrm{II})$ ion from complexation with ferrozine. Briefly, 50 $\mu \mathrm{L}$ of the sample or standard was mixed with $10 \mu \mathrm{L}$ of $\mathrm{FeCl}_{2}$ and $10 \mu \mathrm{L}$ ferrozine was introduced after 5 minutes. Absorbance was read at $562 \mathrm{~nm}$ after 10 minutes incubation at room temperature. Ethylene diamine tetraacetic acid (EDTA) served as the standard. Gallic acid was used as a comparison group to the coffee extracts. The procedure was performed in six replicates. The metal chelating activity was computed using the formula:

$\% \mathrm{MCA}=\frac{\mathrm{A} \text { control }-\mathrm{A} \text { extract }}{\mathrm{A} \text { control }} \times 100$

\section{Statistical tests}

Data on levels of ochratoxin A, total phenolic content and antioxidant activities were presented using mean \pm standard deviation. One Way Analysis of Variance (ANOVA) with post hoc Tukey HSD test was utilized to determine significant differences of the means. Statistical analysis was performed using SPSS 20.0 for Windows at $\alpha=0.05$.

\section{RESULTS}

\section{Phenolic content of defective and non-defective coffee bean samples}

In Table 1, the composition of the coffee bean extracts reveals that the total phenolic content of non-defective green coffee beans was higher compared to the total phenolic 
Table 1: Total phenolic content of coffee samples

\begin{tabular}{llc}
$\begin{array}{l}\text { Sample } \\
\text { code }\end{array}$ & Description & $\begin{array}{c}\text { TPC } \\
\text { (g GAE*100 } \text { - }^{-1} \\
\text { DW of coffee }\end{array}$ \\
\hline GCB1 & Non-defective coffee beans & $14.05^{\mathrm{a}} \pm 0.08$ \\
GCB2 & Black coffee beans & $12.57^{\mathrm{b}} \pm 0.07$ \\
GCB3 & Immature coffee beans & $11.83^{\mathrm{c}} \pm 0.07$ \\
RCB1 & Non-defective coffee beans, & $6.54^{\mathrm{d}} \pm 0.04$ \\
& medium roast & \\
RCB2 & Black coffee beans, medium roast & $5.87^{\circ} \pm 0.04$ \\
RCB3 & Immature coffee beans, medium & $7.84^{\mathrm{f}} \pm 0.05$ \\
& roast & \\
\hline
\end{tabular}

Means with different letters are significantly different $(\rho<0.05), n=5$

Table 2: Fungal contaminants and ochratoxin A in coffee bean samples

\begin{tabular}{|c|c|c|}
\hline Sample code & OTA level $\left(\mu g^{*} \mathrm{~kg}^{-1}\right)$ & Fungal species \\
\hline GCB1 & ND & $\begin{array}{l}\text { Fusarium oxysporum } \\
\text { Aspergillus ochraceus }\end{array}$ \\
\hline GCB2 & $23.02^{\mathrm{a}} \pm 2.32$ & $\begin{array}{l}\text { Aspergillus niger } \\
\text { Aspergillus ochraceus } \\
\text { Fusarium oxysporum }\end{array}$ \\
\hline GCB3 & $17.14^{b} \pm 1.57$ & $\begin{array}{l}\text { Fusarium oxysporum } \\
\text { Aspergillus ochraceus } \\
\text { Rhizopus stolonifer }\end{array}$ \\
\hline RCB1 & ND & None \\
\hline RCB2 & $5.57^{\mathrm{c}} \pm 0.07$ & None \\
\hline RCB3 & $6.79^{d} \pm 0.67$ & None \\
\hline
\end{tabular}

Means with different letters are significantly different $(\rho<0.05), n=3$. GCB1: Green coffee bean (no defect), GCB2: Green coffee bean (black), GCB3: Green coffee bean (immature), RCB1: Roasted coffee bean (no defect), RCB2: Roasted coffee bean (black), GCB3: Roasted coffee bean (immature)

content of black and immature green coffee bean samples. Upon roasting, the total phenolic content of all coffee samples decreased. Roasted immature coffee beans had the highest phenolic content among roasted coffee bean samples.

\section{Fungal contaminants and ochratoxin $A$ in coffee bean samples}

Table 2 shows the level of ochratoxin A and fungal species in the coffee bean samples. It can be observed that in all green coffee bean samples, the most common fungal contaminants were Aspergillus ochraceus and Fusarium oxysporum. Both black and immature green coffee beans were contaminated with ochratoxin A and ochratoxigenic fungal species. Both black and immature green coffee beans were contaminated with ochratoxin A and ochratoxigenic fungal species. Non-defective green coffee beans had no detectable ochratoxin A. After medium roasting, the OTA levels in defective green coffee beans decreased, although roasted immature coffee beans had higher OTA level than roasted black coffee beans. Fungal growth was not observed in all roasted coffee bean samples.

\section{Radical scavenging activity}

The DPPH radical scavenging activities of defective and non-defective coffee extracts are presented in Fig. 1. The degree of radical scavenging activity was based on the degree of discoloration of DPPH radical. It was observed that the radical scavenging activities of both defective and non-defective coffee extracts exhibited concentrationdependence. In all coffee bean samples, roasted coffee beans (medium roast) exhibited higher scavenging activities compared to green coffee beans.

It was also observed that non-defective coffee bean samples had higher $\%$ scavenging activities than defective coffee bean samples. The lowest activity was noted in defective immature green coffee beans. However, all coffee extracts had statistically lower radical scavenging activities compared to L-ascorbic acid and gallic acid $(p<0.05)$.

\section{Metal chelating activity}

Based from the results in Fig. 2, all coffee bean extracts exhibited moderate to high metal chelating activities ( $>60 \%$ chelating activity) which also exhibited concentration-dependence. Generally, roasted coffee beans had significantly higher metal chelating activities against $\mathrm{Fe}^{2+}$ ion compared to green coffee bean samples $(\phi<0.05)$. Among the coffee bean extracts, the highest metal chelating activity was observed in roasted non-defective coffee beans while the lowest activity was observed in immature coffee beans. However, the metal chelating activity of EDTA and gallic acid were statistically higher compared to the activities of all coffee bean samples $(\mathrm{p}<0.05)$.

\section{DISCUSSION}

Coffee is one the major agricultural products of Atok, Benguet, Philippines. This municipality is characterized by high altitude, making it suitable to grow the Arabica coffee variety. The coffee growers in the municipality do not use herbicides and pesticides, since the coffee organizations do not promote chemicals in farming. However, due to humid conditions and low temperature, the drying of coffee beans becomes inefficient which makes coffee beans susceptible to fungal contamination. An insufficient drying leads to fungal contamination and production of defective coffee beans, thereby decreasing the quality of coffee brews.

To ensure a high quality of coffee brews, defective coffee beans do not reach the market since coffee beans are sorted manually by coffee farmers prior to packing and roasting. Some of the defects in coffee beans include black beans, infested beans, broken beans, sour beans, and immature beans, although other coffee samples such as husk beans, or coffee samples with foreign matter or composed of several varieties of coffee are considered as defects (PNS/BAFPS 01:2012). Defective coffee beans are typically consumed as beverage by the farmers and coffee growers. The common 


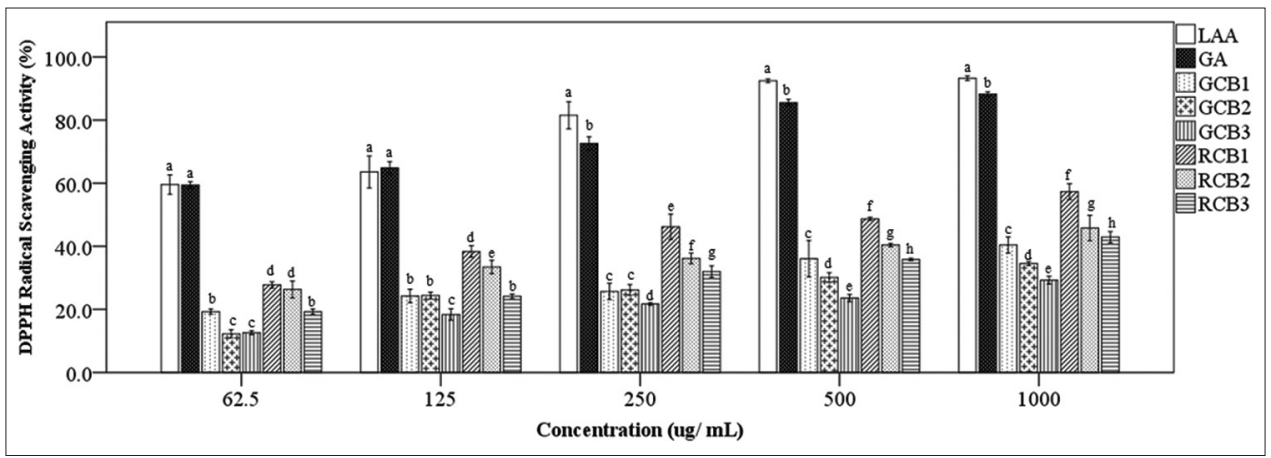

Fig 1. Comparison of \% radical scavenging activity of coffee bean extracts compared to L-ascorbic acid and gallic acid in a DPPH system. $\mathrm{LAA}=\mathrm{L}$-ascorbic acid, GA = Gallic acid, GCB1 = Green coffee bean (non-defective), GCB2 = Green coffee bean (black), GCB3 = Green coffee bean (immature), RCB1 = Roasted coffee bean (non-defective), RCB2 = Roasted coffee bean (black), GCB3 = Roasted coffee bean (immature) . Means with different letters are significantly different $(p<0.05), \mathrm{n}=6$.

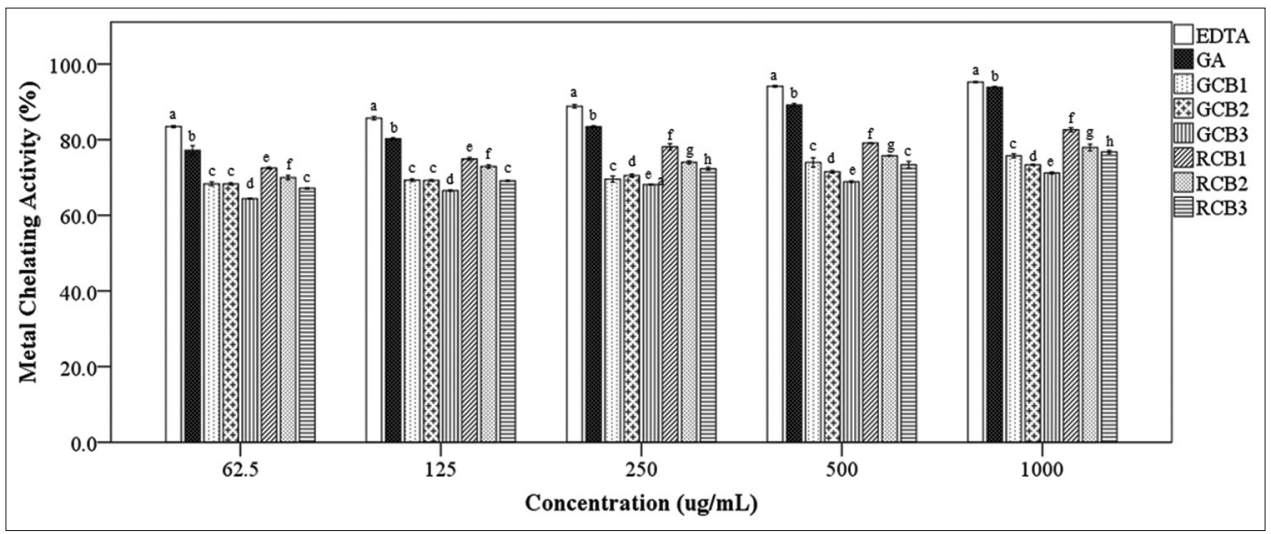

Fig 2. Comparison of \% metal chelating activity of coffee extracts, gallic acid and EDTA. LAA = L-Ascorbic Acid, GA = gallic acid, GCB1 = Green coffee bean (non-defective), GCB2 = Green coffee bean (black), GCB3 = Green coffee bean (immature), RCB1 = Roasted coffee bean (nondefective), $\mathrm{RCB} 2$ = Roasted coffee bean (black), GCB3 = Roasted coffee bean (immature). Means with different letters are significantly different $(p<0.05), n=6$.

types of coffee defects investigated in this study were black and immature coffee beans. Coffee beans are classified as black if half or more than one half of the coffee bean is black while immature beans appear gray or greenish often with a wrinkled surface (PNS/BAFPS 01:2012). Black coffee beans were less preferred by farmers due to their poor flavour and susceptibility to easy charring during roasting. Hence, it was a common practice to mix non-defective coffee beans with defective coffee beans to improve the taste of the resulting coffee brew.

Due to an earlier report on the incidence of ochratoxin A in defective coffee beans (Taniwaki et al., 2014), this study investigated the incidence of ochratoxin $A$ and presence of ochratoxigenic fungal species in defective coffee beans from a temperate area in the Cordillera Administrative Region, especially since the environmental conditions may promote fungal contamination during post-harvest processing of coffee. It has to be noted that other notable compounds which have been extensively published elsewhere regarding other contents of coffee extracts such as phenolic compounds (Ramalakshmi et al., 2009; Górnaś et al., 2016), biogenic amines such as putrescine, cadaverine, spermidine, spermine and tryptamine (Vasconselos et al., 2007), proteins, carbohydrates, fatty acids (Oliveira et al., 2006), several volatile compounds (Toci and Farah, 2008) and diterpenes such as cafestol and kahweol (Cavin et al., 1998). However, unwanted contaminants such as mycotoxins may also be present (Taniwaki et al., 2014). Culliao and Barcelo (2015) have initially reported the incidence of ochratoxin A, sterigmatocystin and patulin in coffee samples from Benguet, Philippines although none has been reported on roasted coffee samples and defective coffee beans.

Among the different mycotoxins, the most commonly studied contaminant in coffee was ochratoxin A, a nephrotoxic, carcinogenic and immunosuppresive toxin produced by genera Aspergillus and Penicillium (JECFA, 2001; Vanesa and Ana, 2013). Our results reveal that the levels of OTA in black defective green coffee beans agrees with the OTA level reported in the study of Taniwaki et al (2014) $\left(25.7 \mu \mathrm{g}^{*} \mathrm{~kg}^{-1}\right)$. However, the reported OTA level in immature defective coffee beans was much higher in our study. After medium roasting, it was also revealed that the 
OTA level in both defective coffee samples decreased, but was still higher than $5 \mu \mathrm{g}^{*} \mathrm{~kg}^{-1}$, which is the maximum allowable limit for OTA in roasted coffee (European Commission, 2006). The presence of this fungal toxin in immature and black defective coffee beans is a concern to needs to be addressed to consumers of defective coffee beans. Furthermore, roasting may decrease the analytical ochratoxin A content of defective green coffee beans, but not its genotoxic properties (Lerda et al., 2013).

This study has also found out that both types of defective coffee were contaminated with ochratoxin A and ochratoxigenic fungal species such as Aspergillus ochraceus (section Circumdati) and Aspergillus niger (section Nigri). Aspergillus species which belong to section Circumdati and Nigri were also reported to be present in black and immature defective coffee beans (Taniwaki et al., 2014). All Aspergillus isolates in the study were ochratoxigenic. Our results agree with the report of Alvindia and de Guzman (2016) that some of the ochratoxigenic fungal species in Arabica coffee beans were Aspergillus niger and Aspercillus ochraceus. However, other species such as Aspergillus carbonarius, Aspergillus japonicus, Aspergillus westerdijkiae, and Penicillium verruculosum were not isolated from the coffee samples. The presence of ochratoxin A and absence of fungal species in roasted coffee samples imply that defective coffee beans may contribute to the OTA contamination of coffee brews, especially if the green coffee beans were not sorted prior to roasting.

Despite the contamination of the samples by ochratoxigenic fungi and ochratoxin A, both green and roasted defective coffee beans have exhibited notable antioxidant activities. Based from the results presented in Table 1, non-defective green coffee beans had the highest total phenolic compounds to defective green coffee beans and the roasted coffee samples. Troup et al. (2015) reported that low molecular weight polyphenolic compounds contributed greatly to the antioxidant activity of coffee brews. In addition, the antioxidant property of green coffee bean extracts is chlorogenic acid (Chachurin et al., 2002; Ramalakshmi et al., 2007; Ramalakshmi et al., 2009; Jeszka-Skowron et al., 2016). Our results agree with an earlier report by Ramalakshmi et al (2007) that defective coffee beans had lower phenolic content than non-defective coffee beans, although this was not a similar observation in roasted coffee samples. Roasted immature coffee beans had higher phenolic content compared to roasted non-defective coffee samples. This may seem contradicting since immature coffee beans may not have an opportunity to accumulate phenolic compounds compared to mature coffee beans.

The radical scavenging activity exhibited by both nondefective and defective coffee samples (green and roasted coffee beans) were significantly lower compared to the standards L-ascorbic acid and gallic acid in a DPPH system and lower metal chelating activity compared to EDTA and gallic acid $(p<0.05)$ in all concentrations. However, the crude extracts may reflect a more accurate antioxidant activity of the coffee beans when consumed. Among the coffee samples, roasted non-defective and defective coffee beans exhibited significantly higher DPPH radical scavenging activity (Fig. 1) and metal chelating activity against $\mathrm{Fe}^{2+}$ ion (Fig. 2), despite having significantly lower total phenolic content compared to green coffee beans $(p<0.05)$.

The metal chelating activity of coffee bean extracts has been attributed to the contribution of low-molecular weight phenolic compounds (Gornas et al., 2016), caffeic acid (Generato-Mattos et al., 2015) and melanoidins (Vignoli et al., 2011; Troup et al., 2015). While metal chelating activity shows an increasing trend relative to the total phenolic compounds in green coffee beans, this was not observed in roasted coffee samples. However, it was observed that roasted non-defective coffee beans exhibited significantly higher antioxidant activities compared to roasted defective coffee beans. The results in this study agrees with the study of Górnaś et al (2016), indicating a lower contribution of phenolic compounds to metal chelating activities of roasted coffee bean extracts.

The reduction of total phenolic content in roasted coffee samples was generally attributed to roasting due to the thermal instability of phenolic compounds (Górnaś et al., 2016). This explains why roasted coffee samples had lower total phenolic content compared to green coffee bean samples. However, roasting also promotes the formation of several compounds such as melanoidins due to caramelization and Maillard reactions (Chachurin et al., 2002; Franca et al., 2005b; Troup et al., 2015), and melanoidin-like compounds which forms polymers with sugars, amino acids and other remaining phenolic compounds (Takenaka et al., 2005). Roasting coffee beans increase the formation of other antioxidants compared to the loss of phenolic compounds (Vignoli et al., 2011; Opitz et al., 2014) thereby compensating the loss of antioxidant activities during roasting (Liang \& Kitts, 2014). This may explain why the radical scavenging activity and metal chelating activity of both non-defective and defective coffee beans increased even if their total phenolic content decreased after roasting.

\section{CONCLUSION}

This study shows that defatted extracts of defective green and roasted Arabica coffee beans from Benguet, Philippines 
possess moderate to high antioxidant activities. Roasting the coffee beans decreased the total phenolic content of defective green coffee beans but increased their radical scavenging activity in a DPPH system and chelation of $\mathrm{Fe}^{2+}$ ions. The activities, however, were considerably lower than the standard compounds such L-ascorbic acid, gallic acid and EDTA. The defective coffee bean samples in this study were contaminated with ochratoxigenic fungal species and ochratoxin A, although roasting decreased their analytical OTA content. This study suggests that isolating antioxidant compounds from defective coffee beans can further extend their use for other food or medical applications. While the data in this study are limited to few coffee samples, the results imply that consuming defective coffee beans may have possible health impacts to consumers. Defective coffee beans should be further processed to isolate antioxidants and remove ochratoxin A.

\section{ACKNOWLEDGMENT}

This study was made possible through the grant provided by the Commission on Higher Education Grants-in-Aid, with financial support from Saint Louis University under Research Matching Grant No. 2014.3.SNS.2.

\section{Author's contributions}

J.M.B: Study design, statistical analysis, supervision of study, wrote the article. R.C.B.: Discussion on antioxidant assays, co-wrote the article. A.M.A.: Participated in performing assays, contributed to writing of discussions.

\section{REFERENCES}

Alvindia, D. G. and A. M. Acda. 2010. Mycoflora of coffee beans in the Philippines. Int. Soc. Southeast Asian Agric. Sci. 16: 116-125.

Alvindia, D. G. and M. F. de Guzman. 2016. Survey of Philippine coffee beans for the presence of ochratoxigenic fungi. Mycotoxin Res. 32: 61-67.

Batista, L. R., S. M. Chalfoun, C. F. Silva, M. Cirillo, E. A. Varga and R. F. Schwan. 2009. Ochratoxin A in coffee beans (Coffea Arabica L.) Processed by dry and wet methods. Food Control. 20: 784-790.

Cavin, C., D. Holzhaauser, A. Constable, A. C. Huggett and B. Schilter. 1998. The coffee-specific diterpenes cafestol and kahweol protect against aflatoxin B1-induced genotoxicity through a dual mechanism. Carcinogenesis. 19: 1369-1375.

Chachurin, P., J. M. Ames and M. D. Del Castillo. 2002. Antioxidant activity of coffee model systems. J. Agric. Food Chem. 50: 3751-3756.

Clarke, G., K. N. Ting, C. Wiart and J. Fry. 2013. High correlation of 2, 2-diphenyl-a-picrylhydrazyl (DPPH), ferric reducing activity potential, and total phenolic contents redundancy in use of all three assays to screen for antioxidant activity of extracts of plants from the Malaysian forest. Antioxidants. 2: 1-10.

Craig, A. P., A. S. Franca and L. S. Oliveira. 2012. Discrimination between defective and non-defective roasted coffee by diffuse reflectance infrared Fourier transform spectroscopy. LWT Food Sci Technol 47: 505-511.

Culliao, A. G. L. and J. M. Barcelo. 2015. Fungal and mycotoxin contamination of coffee beans in Benguet province, Philippines. Food Addit. Contam. Part A. 32: 250-260.

European Commission. 2006. Commission regulation (EC) No 1881/2006 of 19 December 2006, setting maximum levels for certain contaminants in foodstuffs. Official J. Eur Union. 364: $1 \mathrm{e} 25$.

Franca, A. S., L. S. Oliveira, J. C. F. Mendonca and X. A. Silva. 2005a. Physical and chemical attributes of defective crude and roasted coffee beans. Food Chem. 90: 89-94.

Franca, A. S., J. C. F. Mendonca and S. D. Oliveira. 2005b. Composition of green and roasted coffees of different cup qualities. LWT Food Sci. Technol. 38: 709-715.

Genaro-Mattos, T. C., A. Q. Maurício, D. Rettori, A. Alonso and M. Hermes-Lima. 2015. Antioxidant activity of caffeic acid against iron-induced free radical generation - A chemical approach. PLoS One. 10(6): e0129963.

Górnaś, P., K. Dwiecki, A. Siger, J. Tomaszewska-Gras, M. Michalak and K. Polewski. 2016. Contribution of phenolic acids isolated from green and roasted boiled-type coffee brews to total coffee antioxidant capacity. Eur. Food Res. Technol. 242: 641-653.

JECFA. 2001. Joint Expert Committee on Food Additives. Safety Evaluation of Certain Mycotoxins in Food. WHO Food Additives, Series 47. FAO Food and Nutrition Paper, 74, $292 \mathrm{e} 322$.

Jeszka-Skowron, M., A. Sentkowska, K. Pyrzynska and M. P. De Pena. 2016. Chlorogenic acids, caffeine content and antioxidant properties of green coffee extracts: Influence of green coffee bean. Eur. Food Res. Technol. 242: 1403-1408.

Le, K., F. Chiu and K. Ng. 2007. Identification and quantification of antioxidants in Fructus lycii. Food Chem. 105: 353-363.

Lerda, D., P. Pelliccioni, M. Biagi, G. Scalone, R. Vallejos, M. Stout, J. Mezzano, C. Flanagen and N. Litterio. 2013. Roasting of coffee beans (Coffea arabica) artificially contaminated with ochratoxin A strongly reduces the analytical ochratoxin A content but not the genotoxic effects. Curr. Top. Toxicol. 9: 75-80.

Liang, N. and D. D. Kitts. 2014. Antioxidant property of coffee components: Assessment of methods that define mechanism of action. Molecules. 19: 19180-19208.

Noonim, P., W. Mahakarnchanakul, K. F. Nielsen, J. C. Frisvcad and R. A. Samson. 2008. Isolation, identification and toxigenic potential of ochratoxin A-producing Aspergillus species from coffee beans grown in two regions of Thailand. Int. J. Food Microbiol. 128: 197-202.

Oliveira, L. S., A. S. Franca, J. C. F. Mendonca and M. C. Barros-Junior. 2006. Proximate composition and fatty acids profile of green and roasted defective coffee beans. LWT Food Sci. Technol. 39: 235-239.

Oliveira, G., D.M. da Silva, R.G.F.A. Pereira, L.C. Paiva, G. Prado and L.B. Batista. 2013. Effect of different roasting levels and particle sizes on ochratoxin A concentration in coffee beans. Food Control 34: 651-656.

Opitz, S. E. W., S. Smrke, B. A. Goodman, M. Keller, S. Schenker and C. Yeretzian. 2014. Antioxidant generation during coffee roasting: A comparison and interpretation from three complementary assays. Foods. 3: 586-604.

PNS/BAFPS 01:2012. Green Coffee Beans - Specifications. Bureau of Agriculture and Fisheries Products Standards. Department of Agriculture. Diliman, Quezon City, Philippines.

Ramalakshmi, K., I. R. Kubra and L. J. M. Rao. 2007. Physicochemical characteristics of green coffee: Comparison of graded and 
defective beans. J. Food Sci. 72: 333-337.

Ramalakshmi, K., I. R. Kubra and L. J. M. Rao. 2008. Antioxidant potential of low-grade coffee beans. Food Res. Int. 41: 96-103.

Ramalakshmi, K., L. J. M. Rao, Y. Takano-Ishikawa and M. Goto. 2009. Bioactivities of low-grade green coffee and spent coffee in different in vitro model systems. Food Chem. 115: 79-85.

Saeed, N., M. R. Khan and M. Shabbir. 2012. Antioxidant activity, total phenolic and total flavonoid contents of whole plant extracts Torilis leptophylla L. BMC Complement. Altern. Med. 12: 1-12.

Samson, R. A., P. Noonim, M. Meijer, J. Houbraken, J. C. Frisvad and J. Varga. 2007. Diagnostic tools for identifying black aspergilli. Stud. Mycol. 59: 129-145.

Takenaka, M., N. Sato, H. Asakawa, X. Wen, M. Murata and S. Homma. 2005. Characterization of a metal-cheating substance in coffee. Biosci. Biotechnol. Biochem. 69: 26-30.

Taniwaki, M. H., A. A. Teixeira, A. R. R. Teixeira, M. V. Copetti and B. T. lamanaka. 2014. Ochratoxigenic fungi and ochratoxin $A$ in defective coffee beans. Food Res. Int. 61: 161-166.

Toci, A. Y. and A. Farah. 2008. Volatile compounds as potential defective coffee beans' markers. Food Chem. 108: 1133-1141.

Troup, G. J., L. Navarini, F. S. Liverani and S. C. Drew. 2015. Stable radical content and antiradical activity of roasted Arabica coffee: From in-tact bean to coffee brew. PLoS One 10: e0122834.

Vanesa, D. and P. Ana. 2013. Occurrence of ochratoxin A in coffee beans, ground roasted coffee and soluble coffee and method validation. Food Control. 30: 675-678.

Vignoli, J. A., D. G. Bassoli and M. T. Benassi. 2011. Antioxidant activity, polyphenols, caffeine and melanoidins in soluble coffee: The influence of processing conditions and raw material. Food Chem. 124: 863-868.

Vasconselos, A. L. S., A. S. Franca, M. B. A. Gloria and J. C. F. Mendonca. 2007. A comparative study of chemical attributes and levels of amines in defective green and roasted coffee beans. Food Chem. 101: 26-32. 